\title{
COMPARISON OF THE QUALITY OF THREE TYPES OF YOGURT. THE IMPACT OF TAPIOCA POWDER ON THE CHARACTERISTICS OF YOGURT
}

\author{
MOGA Valentina Mădălina ${ }^{1}$ \\ 1"Terezianum" Technological High School of Food Industry, moga.madalina25@yahoo.ro
}

\begin{abstract}
This research presents a comparison between three types of yogurt: classic yogurt without addition, yogurt with added skimmed milk powder (the most common yogurt additive) and yogurt with tapioca. The aim of the research is to identify whether there are differences between these three products and what is the impact of tapioca powder on the characteristics of yogurt. Experimental determinations were performed such as: sensory analysis, textural analysis, analysis of physical parameters (acidity, lactose content, syneresis).
\end{abstract}

KEY WORDS: yogurt, quality, syneresis,

\section{INTRODUCTION}

Yogurt is one of the most consumed products in the category of dairy products. Its popularity is due to its health benefits, but it is also due to its sensory characteristics. The formation of the flavor and texture of yogurt depends on a number of factors: the compositional properties of raw milk, the type and amount of microorganisms used in the coagulation process, preliminary treatments applied to milk before sowing (homogenization, pasteurization), but also the time and temperature incubation. [1]

The current trend of producers is to test new natural ingredients and incorporate them into fermented dairy products in order to improve their sensory and texture attributes, obtaining functional dairy products. [2]

Normally yogurt contains two ingredients, milk and dairy crops. With the evolution of science, yogurt has become one of the most researched products in the category of fermented dairy products. The aim was to improve its properties and also reduce the risk of textural defects, such as the elimination of whey, called syneresis, but also the improvement of taste and aroma. [3]

To achieve these things proved to be useful to add skim milk powder, whey proteins and stabilizers (starch, gums, gelatin). In terms of improving nutritional qualities, prebiotics, prebiotics, essential fatty acids and omega 3, fiber and other functional foods have been added [4]which along with the improvement of the nutritional properties bring a contribution in the improvement of the texture. [5]

Also, to improve the consistency of yogurt, there are research directions where different natural ingredients have been used, such as vegetable products, extracts or spices, which have led to obtaining functional dairy products of innovative type. [6]

Tapioca starch is obtained from the roots of the cassava plant, which is found in equatorial regions between the Tropic of Cancer and the Tropic of Capricorn. The name cassava is generally applied to the roots of the plant, whereas tapioca is the name given to starch and other processed products. The large central pith of the cassava roots is the starch-reserve flesh and can range in starch content from as low as $15 \%$ to as high as $33 \%$. [7]

Tapioca is a white to off-white powder with a moisture below $13 \%$. The $\mathrm{pH}$ of a slurry in water is neutral. Tapioca Starch is very bland and clean in flavor and is not masking the flavours used. It is used as a water binding and texturizing agent. It has a high viscosity, water-holding capacity and binding abilities. [8]

Tapioca starch is differentiated from other starches by its low level of residual materials, lower amylose content than for other amylose-containing starches, and high molecular weights of amylose and amylopectin. Starch modifications can be classified as physical modifications, chemical modifications, and genetic modifications [7] Generally, normal native starches consist of a mixture of $15-30 \%$ amylose and $70-85 \%$ amylopectin. Amylose contributes to the gelling property of starch whereas amylopectin contributes high viscosity. [8]

The most common applications of tapioca starch in the food industry are as a thickener for cake creams and sauces, in the manufacture of biscuits to improve texture, in the manufacture of gluten-free bread, but also in baby food.

\section{PRODUCT QUALITY ANALYSIS}

The following was used to prepare the yogurts:

Starters and ingredients:

- $\quad$ whole cow's milk purchased from a local producer

- $\quad$ yoghurt starter culture from CHN Hansen

- $\quad$ skimmed milk powder max $1 \%$ fat and 34\% protein from Top Ingredients SRL

- tapioca in the form of a fine white powder with a neutral taste and smell, from BiOrganik Foods Kft

The production technology of the three types of yoghurt is based on the classic yoghurt manufacturing process, and the yoghurt samples were made in laboratory conditions.

The preparation is explained below:

The peculiarities of the preparation flow of the three types of yoghurt counted in the addition of skimmed milk powder in the case of the PLP sample and the addition of tapioca in the case of the PLT sample. The description of the samples can be seen in Table (1).

After mixing the samples with skimmed milk powder or tapioca, the milk samples are pasteurized separately at $90-95 \mathrm{oC}$ for 20 minutes. This operation is important for obtaining high quality products, safe for consumption. 
Table 1. Description of yoghurt samples

\begin{tabular}{|c|c|c|c|c|}
\hline \multirow{2}{*}{$\begin{array}{c}\text { Sample } \\
\text { code }\end{array}$} & Sample name & \multicolumn{3}{|c|}{ Raw materials } \\
\cline { 3 - 4 } & & Milk, \% & $\begin{array}{c}\text { Skimmed milk } \\
\text { powder, } \%\end{array}$ & Tapioca, $\%$ \\
\hline PLI & Natural yoghurt & 100 & - & - \\
\hline PLP & $\begin{array}{c}\text { Yoghurt with addition of skim } \\
\text { milk powder }\end{array}$ & 98 & 2 & - \\
\hline PLT & Yoghurt with addition of tapioca & 98 & - & 2 \\
\hline
\end{tabular}

Heat treatment causes denaturation of whey proteins and complex formation (whey protein - whey protein or whey protein micelles - casein) by binding disulfides, which initiates gelation. [9]

The pasteurized samples are then cooled to an incubation temperature of $42-45 \mathrm{oC}$. After that, it is inoculated with the starter culture.

The milk is packaged in glass jars with a capacity of $250 \mathrm{ml}$ and they are thermostated at a temperature of $42-45 \mathrm{oC}$ for $2: 30$ hours. The fermentation is interrupted when the yoghurt has a $\mathrm{pH}$ between 4.6-4.7 and an acidity between 80-90oT.

Cooling is performed in two stages: pre-cooling to $20 \mathrm{oC}$, for 3 hours to harden the curd and prevent the process of removing the whey, followed by cooling to $2-4 \mathrm{oC}$ for $12 \mathrm{~h}$.

The technological scheme is presented in figure (1).

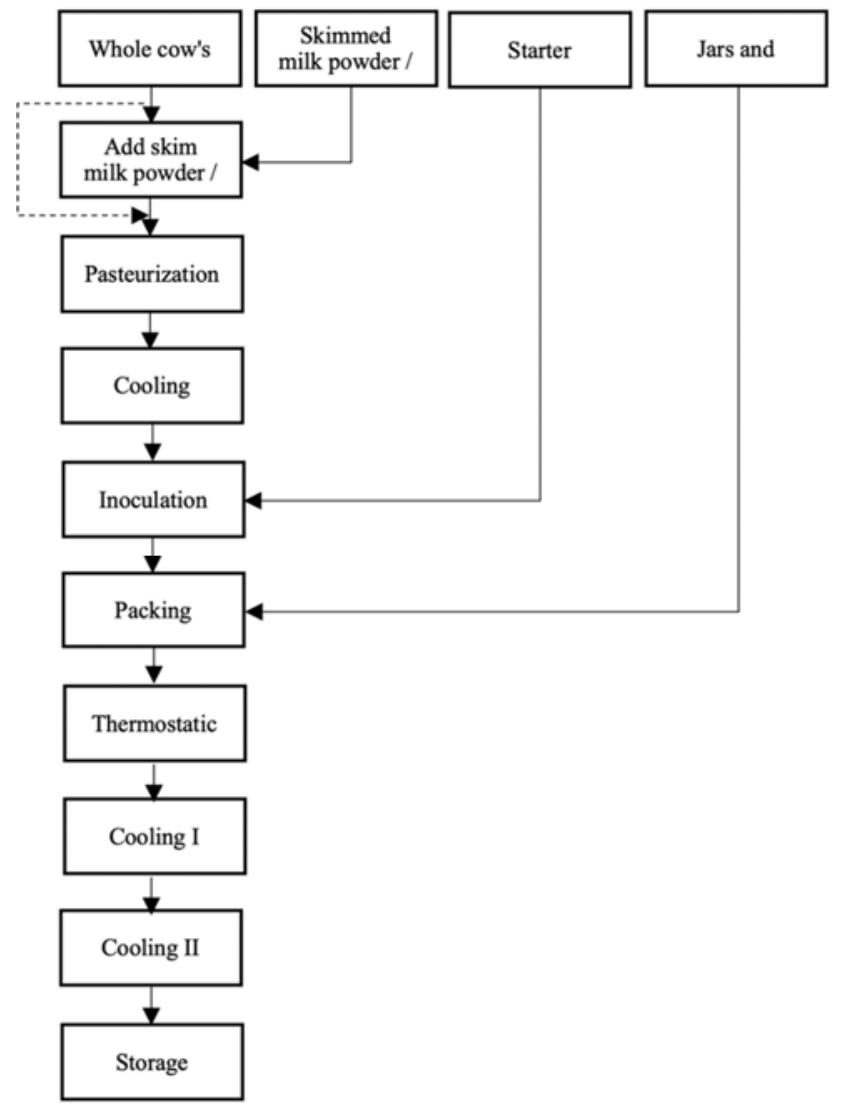

Figure 1. Technological scheme for the preparation of yoghurt samples

\subsection{Methods of analysis}

The yoghurt samples prepared according to the method presented in the previous chapter were analyzed over a period of eighteen days, more precisely on the first day after preparation, on the ninth day and on the eighteenth day.
The sensory analysis of the three yoghurt samples was performed to establish the difference between them, how significant this difference is, but also to establish the sensory properties of the 3 products.

The following aspects were followed through sensory analysis:

- $\quad$ Establishing the sensory properties for products

- $\quad$ Evaluation of sensory characteristics according to SR 6345 (appearance, color, consistency, taste, smell)

- Evaluation of the Textural Profile of the products (stickiness, flouriness, oily texture, consistency, heterogeneity) during eighteen days of storage, in three different days (first day, ninth day and eighteenth day)

In addition to the sensory analysis of yoghurt samples, it was considered necessary to perform physico-chemical analyzes such as:

- Determination of titratable acidity and its evolution during eighteen days of storage, in three different days (first day, ninth day and eighteenth day)

- Determination of lactose and its evolution during eighteen days of storage, on three different days (first day, ninth day and eighteenth day)

- Determination of syneresis and its evolution during eighteen days of storage, in three different days (first day, ninth day and eighteenth day)

\subsubsection{Sensory analysis of yoghurt samples}

Sensory evaluation is the evaluation of the signals that a person receives through his senses: sight, hearing, taste, smell and touch. In a way, the sense organs can be seen as detectors that help transmit information about the properties of food from external stimuli to the brain. [10]

The sensory characteristics of the product and the way they are perceived by the consumer determine the acceptability of the product.

For the sensory evaluation of the yoghurt samples, a sensory analysis evaluation group consisting of 9 members was built. The yoghurt samples were served at a temperature of $4-8 \mathrm{oC}$, in glass cups, respecting the rules of hygiene and food safety.

\section{Triangle test}

The triangle test is a discriminative method used to determine if there is a general difference between two products. [11]

Test Principle: procedure to determine whether there is a perceptible sensory difference or similarity between the samples of two products. The method is a forced selection procedure. The method applies if there can be a difference in a single sensory attribute or in several attributes.

a) Three differently coded samples were presented to the panelists. Two of the three samples were identical (PL01, PL03), which contained yoghurt without additives and a 
different one (PL02), which contained whole milk yoghurt with the addition of $2 \%$ skimmed milk powder. The panelist is instructed to identify the odd sample and record his answer.

b) After analyzing the samples in point a, the evaluators were presented with three more samples, two of the three samples being identical (PL04, PL05), which contained whole milk yoghurt and the addition of $2 \%$ tapioca and a different one (PL06)., which contained whole milk yoghurt with the addition of $2 \%$ skimmed milk powder. The panelist is instructed to identify the odd sample and record his answer.

In both cases the initial coding of the samples was changed to avoid errors.

\section{Evaluation of the sensory characteristics of the three types of yoghurt according to SR 6345}

Test principle: evaluation of each organoleptic characteristic (appearance, color, consistency, taste and smel) by comparison with scoring scales from 0 ... 5 points and obtaining the average score of the group of tasters. [12]

Weighted average score according to, SR 6345, were calculated using the equation (1) and total average score were calculated using the equation (2):

Weighted average score:

$$
\mathbf{P}_{\mathrm{mp}}=\mathbf{P}_{\mathrm{m}} * \mathbf{f}_{\mathbf{p}}
$$

Where from,

Pmp -Weighted average score

Pm - average score ( the arithmetic mean of the results of the 9 members)

Fp - weighting factors

Appearance, color consistency $=1.5$

Taste $=2$

Smell $=0.5$

Total average score:

$$
\mathbf{P}_{\mathbf{m t}}=\sum \mathbf{P}_{\mathbf{m p}}
$$

\section{Evaluation of the textural profile of the three types of yoghurt}

Texture is an important characteristic that influences the acceptability of the product by the consumer. 5 sensory attributes of yoghurts were analyzed.

Evaluated attributes were adapted according to the texture evaluation method described in ,Sensory properties and drivers of liking for Greek yoghurts" [13] which is based on the methods of Drake et al. [14] are:

- Cohesiveness: Amount of product that sticks together during compression

- Graininess: perceived particulates of product in the mouth

- $\quad$ Oily texture: sensation created by milk fat separation

Denseness: Compactness of the cross section, absence of air perceived as the tongue is moved through the sample

Heterogeneity the feeling of heterogeneity of the product when chewed
The yoghurt samples were analyzed by the evaluation committee consisting of 9 members, over 18 days, in 3 different days (first day, ninth day and eighteenth day).

Each member of the commission gave a score for the intensity of the texture characteristics of the three types of yoghurt by comparing with a scoring scale from 1 to 5 points designated after each characteristic as follows:

- $\quad$ Cohesiveness: very little cohesive (1 point) very cohesive (5 points)

- Graininess: foarte puțin granulos (1 point) foarte granulos (5 points)

- $\quad$ Oily texture: very slightly oily (1 point) very oily (5 points)

- Denseness: very dense (1 point) very dense (5 points) (5 points)

Heterogeneity heterogeneous (1 point) homogeneous

\subsubsection{Analysis of physico-chemical parameters}

\section{Titratable acidity}

Principle of the method: a certain amount of yoghurt is titrated with $0,1 \mathrm{n}$ sodium hydroxide solution, in the presence of phenophthalein as an indicator, until the sudden change of color to pink color which persists for 30 seconds. [15]

Procedure: Weigh $10 \mathrm{~g}$ of the yoghurt sample into a $100 \mathrm{ml}$ Erlenmayer beaker over which $20 \mathrm{ml}$ of warm distilled water and 3 drops of phenophthalein have been added. The sample was homogenized and titrated with $0,1 \mathrm{n}$ sodium hydroxide solution until a pink color was obtained, which should persist for 30 seconds.

The acidity is expressed in degrees Thorner and it has been calculated with the following equation (3):

$$
\text { Acidity }{ }^{\circ} \mathrm{T}=\frac{\mathrm{V} * \mathbf{1 0}}{\mathrm{m}}
$$

Wherefrom:

$\mathrm{V}=$ volume of sodium hydroxide solution $0,1 \mathrm{n}$, used for titration, in $\mathrm{ml}$

$10=$ volume of sample

$\mathrm{m}=$ mass of the sample, in $\mathrm{g}$

\section{Determination of lactose content}

The lactose content was determined by polarimetric method II:

Principle of the method: After deproteinization of the milk, the filtrate is polarized and the percentage of lactose is calculated from the measured rotation according to the formula below. [15]

Procedure: $75 \mathrm{ml}$ of the yoghurt sample put in a $100 \mathrm{ml}$ cylinder, treat it with $7.5 \mathrm{ml}$ of $20 \%$ sulfuric acid, then add $7.5 \mathrm{ml}$ of mercuric iodide and make up to $100 \mathrm{ml}$ with $20 \%$ of sulfuric acid. Stir and filter it. A $20 \mathrm{~mm}$ tube is used for polarimetry. The sample is brought to $20 \mathrm{oC}$ and the result is read.

The lactose content is calculated by the following equation (4): 


$$
\text { Lactose } \%=\frac{\alpha * 100}{[\alpha]_{\mathrm{n}}^{20} * 2}
$$

Wherefrom :

$\alpha=$ angle read at the polarimeter

$[\alpha]_{n}^{20}=$ the specific rotation of lactose equal to +52.53

$2=$ wavelength of the polarimetric tube, $\mathrm{dm}$

\section{Syneresis}

The syneresis of the yoghurt samples was determined according to Barkallah's method. [16]

Principle of the method: filter $100 \mathrm{ml}$ of each sample through a funnel lined with filter paper number 1 . After 6 hours of draining, the volume of whey was measured and the following equation (5) was used to calculate the sensitivity to syneresis.

$$
\text { Syneresis, } \%=\frac{V_{1}}{V_{2}} * 100
$$

Wherefrom,

$\mathrm{V}_{1}=$ volume of whey collected after draining;

$\mathrm{V}_{2}=$ volume of the yoghurt sample;

\subsection{Results and discussions}

\subsubsection{Sensory analysis of yoghurt samples Triangle test}

Following the organoleptic evaluation of the experimental samples by the Triangle Test [11]it can be concluded that the PLP and PLT yoghurt samples differ from the PLI control sample.

The evaluators distinguished the three samples, arguing that the PLP and PLT samples look firm, creamy and without whey removal. Also, the PLT sample has a creamier consistency when chewed than the PLP sample and a less astringent taste.

\section{Evaluation of sensory characteristics according to SR 6345}

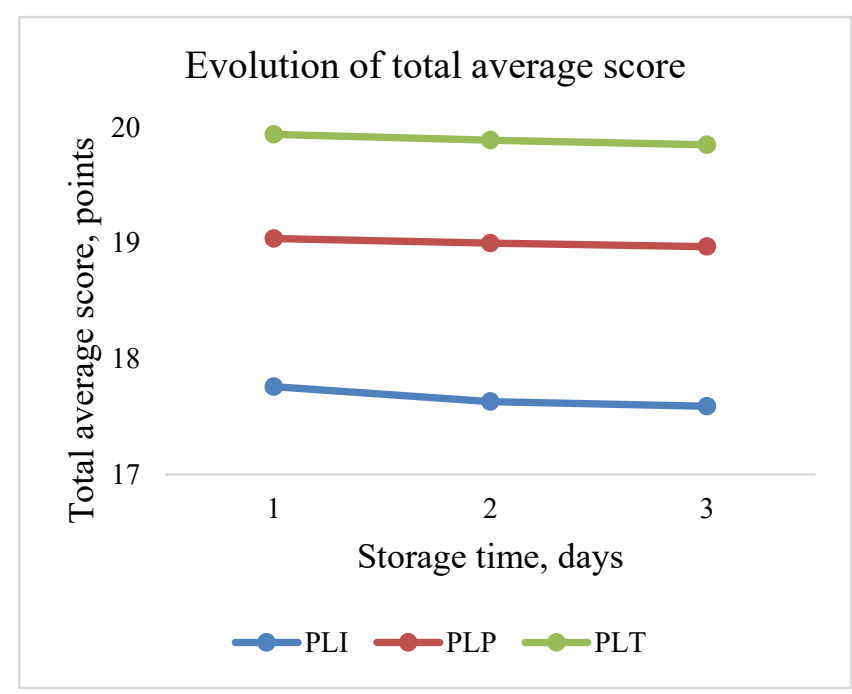

Figure 2. Evolution of the average total score during storage

After the sensory examination of the yoghurt samples and the calculation of the total average score(figure 2) it was found that the PLP and PLT yoghurt samples have very good organoleptic characteristics (Pmt> 18) according to SR 6345 (ASRO, 1995) The tapioca yoghurt sample (PLT) obtained a higher score due to the taste which is firmer and much finer compared to the powdered milk yoghurt (PLP).

The control sample (PLI) obtained a good result $(\mathrm{Pmt}<18)$ according to SR 6345 [12] this is due to the minimum deviations recorded: poor elimination of whey, which also affects the taste. During the retention period, the value of the total average score registers a small decrease.

\section{Evaluation of the textural profile}

- After one day of storage:

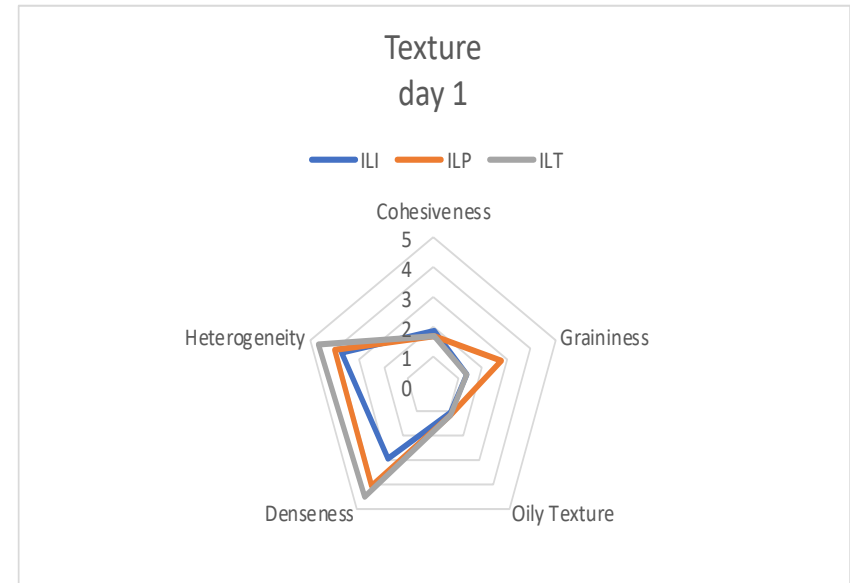

Figure 3. Texture profile expressed after one day of storage

Figure (3) shows that the tapioca yoghurt sample (PLT) has a homogeneous and consistent mass, obtaining better values than in the case of the other samples. The values obtained for cohesiveness, graininsiss and oily texuture are very low.

The yoghurt without additives sample (PLI) recorded average values at heterogeneity and denseness due to the elimination of whey, but does not show high deviations in the case of cohesiveness and graniness, instead it has a much more perceptible oily texture than the other samples. This may be due to fat particles separated on the surface.

In the case of the powdered milk yoghurt sample (PLP) we can observe a much higher value in terms of the cohesiveness due to the proteins contained in the powdered milk. It has a density and homogeneity approximately equal to tapioca yoghurt and also better than plain yoghurt.

- After 9 days of storage 


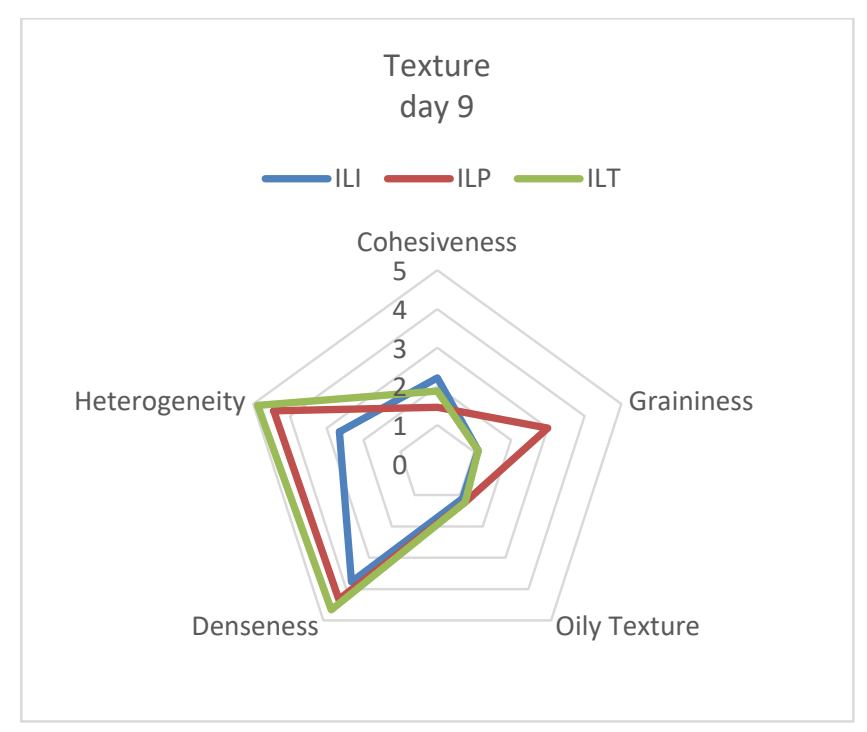

Figure 4. Texture profile expressed after 9 days of storage

The samples were kept for 9 days at refrigeration temperatures and then reanalysed. After 9 days of storage, from graphic figure (4) we can see that the following changes have taken place:

- $\quad$ the PLP sample has become more homogeneous and consistent, but offers a higher feeling of cohesiveness

- $\quad$ the PLI sample has higher adhesive properties and loses its density, but recorded a small increase in the value obtained for heterogeneity

The PLT sample becomes more adhesive and denser when chewed

- After 18 days of storage

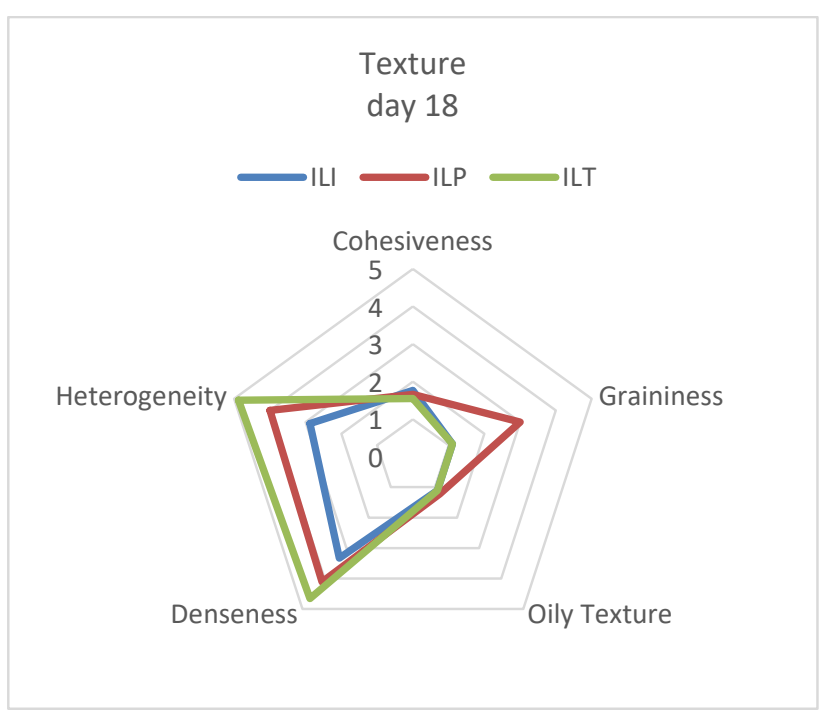

Figure 5. Texture profile expressed after 18 days of storage

The samples were re-analyzed after 18 days of storage at refrigerated temperatures. From figure (5) we can see the following changes:

- $\quad$ Samples have lower values for cohesiveness, but retain their other properties from day 9

\subsubsection{Analysis of physico-chemical parameters}

Following the physico-chemical analyzes of the three yoghurt samples, the values obtained were expressed in the form of graphs showing the evolution during storage of the physico- chemical parameters: acidity (fig. 4.6) lactose content (fig. 4.7) and syneresis (Fig. 4.8).

\section{Titratable acidity}

Acidity is an indicator of freshness. The determination of acidity was made during the period of eighteen days, on the first day, the ninth day and the eighteenth day. The results obtained were represented graphically in figure (6), and results were reported to the value of acidity in ,SR 3665 Yoghurt. Technical quality conditions. "

From the figure (6) it can be seen that the acidity of the 3 samples increases. This is due to the fermentation processes that take place even after the samples are stored. Microorganisms used in inoculation continue to transform lactose and form lactic acid.

The increase in acidity is directly proportional to the shelf life.

The values obtained during storage are normal values for this type of product $\left({ }^{\circ} \mathrm{T}<140\right)$ according to SR 3665 [17].

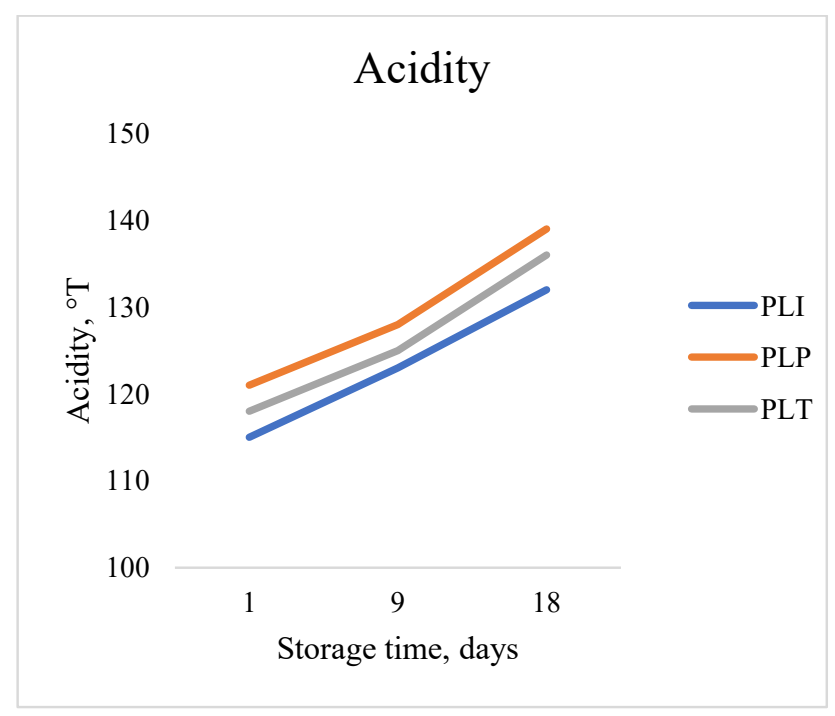

Figure 6. Evolution of acidity

\section{Lactose content}

The lactose content is an important indicator of fermented dairy products, as it is the main substrate involved in lactic fermentation. During the storage period, the lactose content was determined on the first day, the ninth day and the eighteenth day. The obtained results were represented graphically (fig. 4.7) and discussed.

The following figure (7) shows that the sample of yoghurt with added milk powder (PLP) has a higher lactose content due to the supplementation of whole milk with powdered milk which has a high lactose content.

During the storage period, the lactose content decreases, in all three cases under the action of Lactobacillus delbrueckii subsp. bulgaricus and Streptococcus thermophilus which converts lactose into lactic acid. Lactic acid participates in the specific formation of yoghurt flavor. 


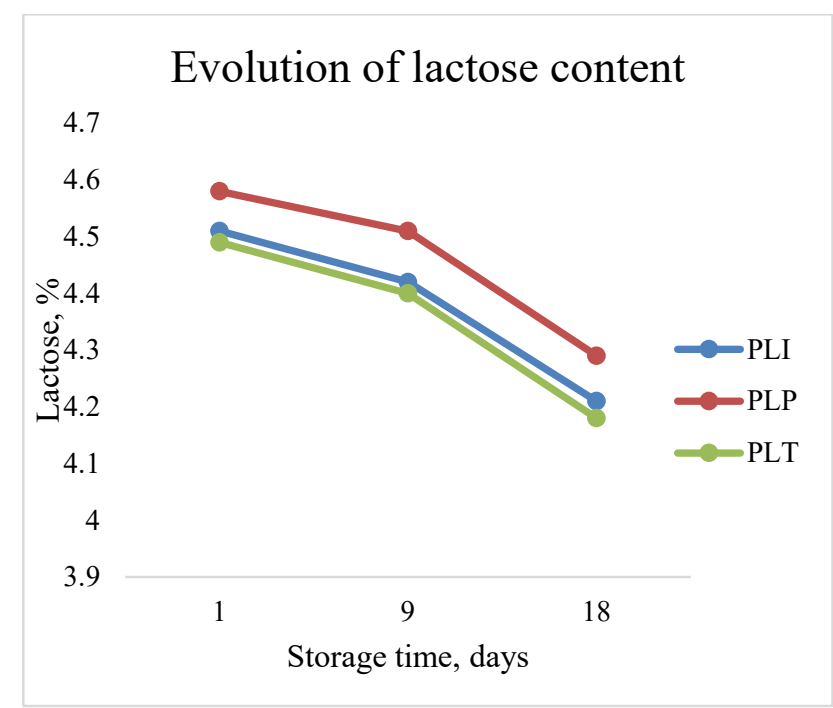

Figure 7. Evolution of lactose content

\section{Syneresis}

Syneresis is considered to be one of the most important parameters that indicate the quality of yoghurt in different stages of storage. The synergy of the yoghurt samples was determined during the storage period: on the first day, the ninth day and the eighteenth day. The results obtained are represented graphically in the following figure (8) and discussed:

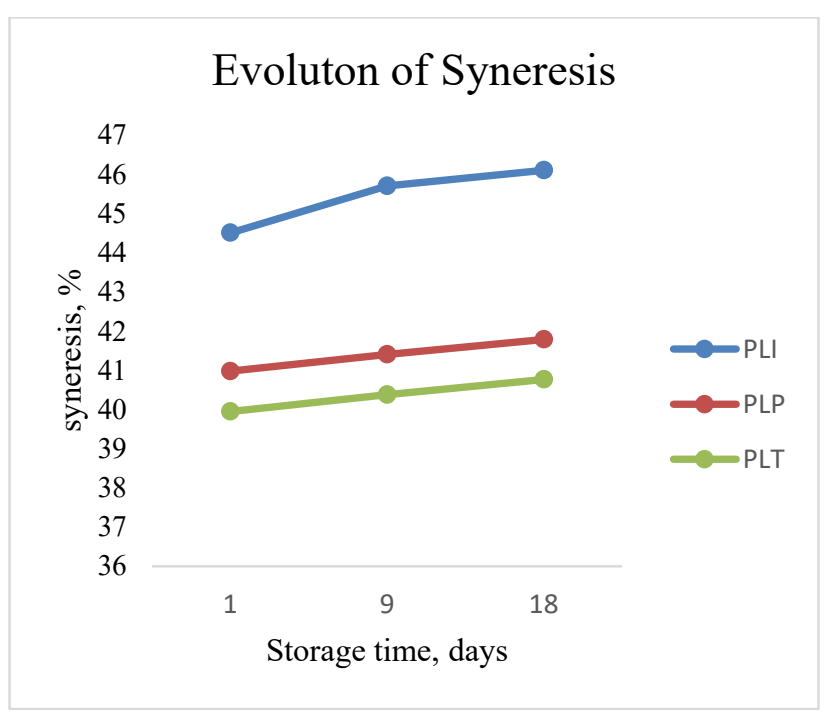

Figure 8. Evolution of syneresis

\section{REFERENCES}

1. Constantinescu, M., \& Tița, M. (2017). Research on the quality assurance of fresh cow's cheese with addition of probiotics. Management of Sustainable Development, 9(2), 11-14.

2. Tița, A. S. (2017). Research on the development and implementation of an innovative dairy product. Management of Sustainable Development, 9(2), 59-61.

3. Moga, V., \& Tița, A. (2020). Marketing aspects of yoghurt enhanced with tapioca. Management of Sustainable Development, 12(2), 12-20.

4. Tița, M., Popovici, C., Tamošaitienè, L., \& Bradauskiene, V. (2020). Biological active compounds
As shown in Figure (8), both PLP and PLT samples performed better than the PLI control sample. The control sample showed a higher increase in syneresis during the storage period, compared to the other samples.

The best result was obtained by the yoghurt sample with the addition of tapioca (PLT), in which lower values of syneresis can be observed by about $1 \%$ compared to the sample with the addition of skimmed milk powder (PLP).

\section{CONCLUSIONS}

Tapioca yoghurt and powdered milk yoghurt have a better consistency and are more homogeneous, compared to yoghurt without additives in which average values were obtained. However, yoghurt with the addition of powdered milk has a graininess sensation that remains even after swallowing.

According to the physico-chemical determinations, it was found that both samples, PLP and PLT, obtained better results than the control sample, PLI.

The acidity of the three yoghurt samples increases during the 18 days, due to the live cultures of yoghurt that continue the process of slow fermentation with accumulation of lactic acid by lactose decomposition. As expected, in the same time frame for each sample, the lactose content decreases.

The lactose content is higher for the PLP sample due to the added skimmed milk powder and therefore it supplements the lactose content of the mixture.

The syneressis of yoghurt samples is higher for the control sample, which shows that the consistency of the yoghurt has been improved by the addition of dry matter. In the case of the PLT sample, a better value was registered, compared to the other samples. During storage, the syneressis of PLP and PLT samples remains almost linear and the PLI sample recorded an increase in whey elimination.

from native food sources for fermented dairy products. Ukrainian Food Journal, 9(1), 36-46.

5. Popovici, C., Tița, M., \& Brînza, R. (2018). Sensory evaluation and rheological behavoir of yogurts prepared from goat milk. 57th Annual scientific conference of University of Ruse and Union of Scientists, 179-186.

6. Tița, M., \& Barca, A. (2017). Comparative analysis of fermented milk products with and without added vegetable ingredients. Bulletin USAVM Animal Science and Biotechnologies, 74(2), 97-101.

7. Breuninger, W. F., Piyachomkwan, K., \& Sriroth, K. (2009, 12). Tapioca/Cassava Starch. Retrieved 04 2020, from Researchgate: https://www.researchgate.net/publication/279433516_Ta piocaCassava_Starch 
8. International Starch Trading. (2003). Tapioca Food Starch. Retrieved 04 2020, from starch.dk: http://www.starch.dk/isi/applic/tapiocafood.htm

9. Barbaros H.Ozer, R. K. (1998). Gelation Properties of Milk Concentrated by Different Techniques. International Diary Jurnal, 8, 793-799.

10. Ottoson, D., \& Shepherd, G. M. (1966). Experiments and Concepts in Olfactory Physiology. Progress in Brain Research (23), 83-138.

11. ISO (2004, 06). ISO 4120:2004 Sensory analysis Methodology Triangle test. ISO/TC 34/SC 12 Sensory analysis.

12. ASRO. (1995, 06). SR 6345 Lapte și produse lactate analiză senzorială. București, Romania.

13. Desai, N. T., Shepard, L., \& Drake, M. A. (2013). Sensory properties and drivers of liking for Greek yogurts. Retrieved from Journal of dairy science: https://www.journalofdairyscience.org/article/S00220302(13)00725-X/pdf
14. Drake, S. L., Lopetcharat, K., \& Drake, M. A. (2009). Comparison of two methods to explore consumer preferences for cottage cheese . Retrieved from Jornal of Dairy https://www.journalofdairyscience.org/article/S00220302(09)71306-2/pdf

15. Tița, M.-A. (2002). Manual de analiză și controlul calităţii în industria laptelui. Sibiu: Editura Universității „Lucian Blaga”.

16. Barkallah, M., Dammak, M., Louati, I., Hadrich, B., Mechichi, T., Ayadi, M., ... Abdelkafi, S. (2017). Effect of Spirulina platensis fortification on physicochemical, textural, antioxidant and sensory properties of yogurt during fermentation and storage. In LWT - Food Science and Technology, 323-330.

17. ASRO. (1999, 05). SR 3665 IAURT Condiţii tehnice de calitate.

București 